\title{
CONTRIBUTION OF SOME ORGANIC AND INORGANIC MATERIALS IN SOIL AGGREGATES FORMATION AND STABILITY UNDER THE EFFECT OF DRYING/WETTING CYCLES
}

Mashhour, A. M. A.

Soils and Water Dept., Agric. Faculty, Al-Azhar University.

\begin{abstract}
This research is trying to identify the contribution of some different organic and inorganic materials besides alternating wetting and drying process in soil aggregates formation and stability. A laboratory incubation experiment was conducted to achieve this purpose, sandy soil was chosen for this study. The incubation treatments included inorganic materials; calcium sulfates and ferrous sulfates and some organic materials; humic acid and plant residues. These materials were added only and with $10 \%$ clay, also, the treatments conducted to drying/wetting cycles and without. The findings of this experiment showed that the soil aggregates formation and stability depended largely on the interaction between organic materials and clay content under drying/wetting cycle's effect. The higher contribution percentage was $9.2 \%$ for humic acid plus $10 \%$ clay after drying/wetting cycle's treatment compared with the control.

Keywords:soil aggregates formation, stable aggregates, dry/wet cycles.
\end{abstract}

\section{INTRODUCTION}

A soil aggregate has been defined as "a naturally occurring cluster or group of soil particles in which the forces holding the particles together are much stronger than the forces between adjacent aggregates", (Soil Science Society of America 1997). The soil aggregation affects the most properties of soil, such as pore size distribution and subsequently, air and water movement, organic matter decomposition and plant growth. Tisdall and Oades (1982) reported that the water-stability of micro-aggregates depends on the persistent organic binding agents and appears to be a characteristic of the soil, independent of management. Bartoli et al. (1992) found that both cementation and aggregate water-stability were increased with increase in adsorbed iron. Rechcigl (1995) found that organic materials promote aggregation stability by gluing particles together within aggregates as well as by coating aggregate surface. As the soil dries, the gel-like glues undergo practically irreversible dehydration, becoming more stable cementing agent that bind clay flocs to one another as well as the silt and sand grains. Puget et al. (1995) concluded that young organic matter was responsible for macroaggregate stability. Miller et al. (1998) found that the stable aggregates percentage in the polyacrylamide treatments ranged from 52 to $97 \%$, vs. 20 $32 \%$ in the control. These treatments significantly increased the percentage of $>4 \mathrm{~mm}$ sized aggregates compared with the untreated aggregates. polyacrylamide was more effective at stabilization in the light to medium textured soils than in the clayey. Bartoli and Dousset (2011) showed that the 
increase in soil organic matter content had beneficial effects on water stable aggregates, particularly for the partially hydrophobic clover and fescue top soils (water stable aggregates of 22.3-44.5\%) against the hydrophilic reference and cereal straw top soils (water stable aggregates of $8.2-12.7 \%$ ). Zhu et al. (2014) reported that the influence of hematite and natural organic matter was demonstrated by aggregation kinetics and critical coagulation concentrations.

Alternating wetting and drying process causes differential expansion and shrinkage, may enhance aggregation in some cases while contributing to aggregate breakdown in others. A particularly destructive condition may result when thoroughly desiccated aggregates are suddenly submerged in water. Wagner et al. (2007) showed that the incorporation of wetting/drying cycles, barley straw and clay content enhance macro-aggregation and development of water-stable aggregates in poorly structured soils. They interpreted the effect of drying/wetting cycles on aggregation as follows; the water drawn into each aggregate over its entire periphery may trap and compress the air originally present in the dry aggregate. As the cohesive strength of the outer part of the cold is reduced by swelling, and as the pressure of the entrapped air builds up in proportion to its compression, the latter may eventually exceed the former and the cold may actually explode. More typically, however, a series of small explosions, each marked by the escape of a bubble of air, shatters the cold into fragments. This destructive process is known as air slaking.This research is an attempt to support the formationandstability of soil aggregates in the sandy soils, which so many benefits for the productivity of these soils, by the addition of some organic and inorganic materials, either with or without adding clay and also under the influence of drying/ wetting cycles.

\section{MATERIALS AND METHODS}

A laboratory experiment was conducted to evaluate the contribution of organic and inorganic materials with drying/wetting cycles on soil aggregates formation and stability. The used organic materials were humic acid $(25 \mathrm{mg}$ $\mathrm{g}^{-1}$ of soil) and plant residues (5\%). The used inorganic materials were calcium sulfate (25 mg g${ }^{-1}$ of soil) and ferrous sulfate $\left(25 \mathrm{mg} \mathrm{g}^{-1}\right.$ of soil). Alternating drying and wetting cycles was for six cycles were allowed to dry for the same time of wet (dry/wet cycle ranged between 14 and 15 day). One kilogram of sandy soil (routine analyses for it are presented in Table 1 according to Klute, 1986 and Page et al., 1982) was putted in PVC pot, and then added the different materials as follow:

1- Calcium sulfates (CS),

2- Calcium sulfates plus $10 \%$ clay (CSC),

3 -Calcium sulfates plus $10 \%$ clay with dry/wet cycles (CSC dry/wet),

4- Ferrous sulfates (FS),

5 - Ferrous sulfates plus $10 \%$ clay (FSC),

6 -Ferrous sulfates plus $10 \%$ clay with dry/wet cycles (FSC dry/wet),

7- Humic acid (HA), 
8- Humic acid plus $10 \%$ clay (HAC),

9- Humic acid plus $10 \%$ clay with dry/wet cycles (HAC dry/wet), 10- Plant residues (PR),

11- Plant residues plus $10 \%$ clay (PRC) and

12- Plant residues plus $10 \%$ clay with dry/wet cycles (PRC dry/wet).

The all materials were loosely mixed into the soil. The all treatments without drying/wetting cycles were irrigated at field capacity for the long of experiment. The pots were subjected for drying/wetting cycles allowed to dry for the same time of wet (drying/wetting cycle was 16 day). The treatments were conducted in three replicates. At the end of experiment (after 3 months), soil samples were taken for aggregate size distribution by dry sieving to calculate the mean weight diameter (MWD) according to Six et al. (2002) as follows: $\mathrm{MWD}=\sum \mathrm{Xi} \mathrm{Wi}, \mathrm{I}=1$ where $\mathrm{X}=$ mean diameter of the considered fraction $\mathrm{mm}, \mathrm{W}=$ weight of the dry sieving fraction $\mathrm{g}$.

Table 1. Analytical data of the investigated soil

\begin{tabular}{|c|c|c|c|c|c|c|c|c|c|c|c|}
\hline $\begin{array}{c}\text { Coarse } \\
\text { sand }\end{array}$ & $\begin{array}{c}\text { Fine } \\
\text { sand } \\
\%\end{array}$ & Silt & $\begin{array}{c}\text { Clay } \\
\%\end{array}$ & $\mid \begin{array}{l}\text { Texture } \\
\text { class }\end{array}$ & \begin{tabular}{|l} 
Bulk \\
density \\
Mg m $^{-1}$
\end{tabular} & \begin{tabular}{|c|} 
Real \\
density \\
Mg m $^{-1}$
\end{tabular} & $\begin{array}{c}\text { Porosity } \\
\%\end{array}$ & $\underset{\mathrm{dSm}^{-1}}{\mathrm{EC}}$ & & 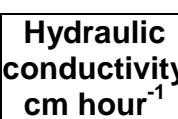 & \\
\hline 43 & 46 & 8 & 3 & sandy & 2.69 & 1.5 & 44.23 & 0.5 & 7.4 & 23.5 & 0.545 \\
\hline
\end{tabular}

\section{RESULTS AND DISCUSSION}

\section{The effect of adding materials.}

Data of the aggregate size distribution and their mean weight diameter (MWD) in Tables 2 and 3 generally, show that the all treatments increased the macro-aggregates and MWD as a result of organic and inorganic materials, clay and the effect of alternating drying and wetting cycles. For the contribution on different materials, compared to the control, aggregation was increased in all treatments. The improvement in aggregation, as indicated by large increase in MWD, was most pronounced for humic acid treatment whereas the contribution percentage was $3.7 \%$ compared with the control.

The beneficial order of enhancement of aggregates formation and stability was as follows: humic acid $(3.7 \%)>$ plant residues $(2.4 \%)>$ calcium sulfate $(1.3 \%)>$ ferrous sulfate $(1.1 \%)$. The effect of the added materials is presented in Fig. 1. This may be attributed to the effect of cementing action of these materials on particles, especially, active humus. Also, when internal surface of humic acid treated aggregates were exposed, the percentage of stable aggregates exceeded the amount expected if the humic was only adsorbed onto external surfaces. This suggested that humic acid had penetrated into aggregates interiors, thereby stabilizing both external and internal aggregates surface. This in agreement with those of Xiao et al. (2008) who found that polysaccharides play a major role in stable soil aggregates formation. 


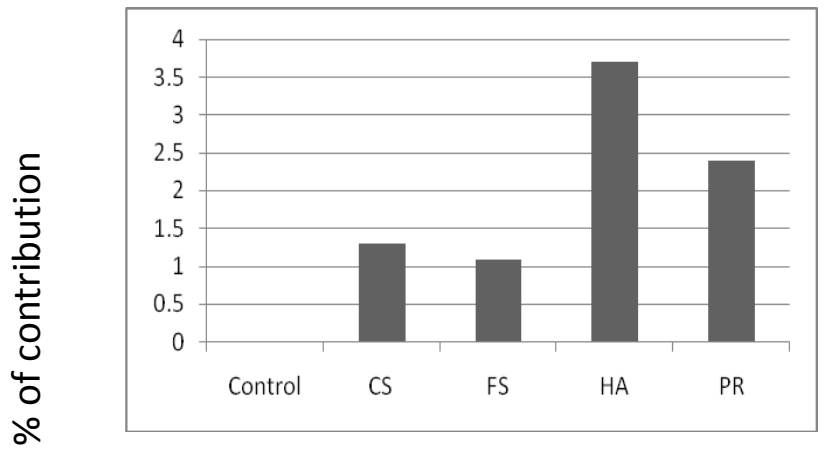

Treatments

Figure 1.the contribution $\%$ of added materials.

\section{2- The effect of adding materials with clay.}

Concerning the interaction of varying materials and clay content, the results of tables 2 and 3 and Fig 2. show that more obtained after treatments plus $10 \%$ clay compared with the previous treatments. The beneficial order of treatments followed by humic acid + clay $(4.8 \%)>$ plant residues + clay and calcium sulfate + clay $(4 \%)>$ ferrous sulfate + clay $(3.6 \%)$. This may be attributed to the effect of clay in coagulation increasing of particles. This in agreement with those of Bartoli and Dousset (2011) and Wagner et al. (2007) who found that the aggregation enhances in clay soils with large straw amendment rates.

Table 2. Aggregate size distribution as affected by different treatments.

\begin{tabular}{|l|c|c|c|c|c|c|c|}
\hline \multirow{3}{*}{ Treatments } & \multicolumn{7}{|c|}{ Aggregate size distribution } \\
\cline { 2 - 8 } & $\mathbf{8 - 2}$ & $\mathbf{2 - 1}$ & $\mathbf{1 - 0 . 5}$ & $\begin{array}{c}\mathbf{0 . 5 -} \\
\mathbf{0 . 2 5}\end{array}$ & $\mathbf{0 . 2 5 - 0 . 1}$ & $\mathbf{0 . 1 - 0 . 0 8}$ & $\begin{array}{c}\mathbf{0 . 0 8 -} \\
\mathbf{0 . 0 0}\end{array}$ \\
\cline { 2 - 8 } & $\mathbf{m m}$ & $\mathbf{m m}$ & $\mathbf{m m}$ & $\mathbf{M m}$ & $\mathbf{m m}$ & $\mathbf{m m}$ & $\mathbf{m m}$ \\
\hline control & 2.1 & 9.15 & 19.75 & 28.5 & 19.75 & 10.75 & 10.0 \\
\hline CS & 2.2 & 9.25 & 19.8 & 28.3 & 20.55 & 10.7 & 9.2 \\
\hline CSC & 2.25 & 10.0 & 20.25 & 27.9 & 20.15 & 10.3 & 9.15 \\
\hline CSC dry/wet & 2.45 & 10.0 & 20.2 & 27.85 & 20.45 & 10.05 & 9.0 \\
\hline FS & 2.15 & 9.35 & 19.8 & 28.4 & 20.4 & 10.5 & 9.4 \\
\hline FSC & 2.4 & 9.45 & 19.85 & 28.35 & 20.45 & 10.3 & 9.2 \\
\hline FSC dry/wet & 2.5 & 9.8 & 20.1 & 27.95 & 20.2 & 10.25 & 9.2 \\
\hline HA & 2.4 & 9.4 & 19.9 & 28.35 & 20.25 & 10.4 & 9.3 \\
\hline HAC & 2.45 & 9.65 & 19.95 & 28.3 & 20.0 & 10.4 & 9.25 \\
\hline HAC dry/wet & 2.7 & 10.2 & 20.75 & 27.65 & 20.1 & 9.45 & 9.15 \\
\hline PR & 2.3 & 9.35 & 19.85 & 27.9 & 20.8 & 10.7 & 9.1 \\
\hline PRC & 2.45 & 9.45 & 19.85 & 28.35 & 20.35 & 10.2 & 9.35 \\
\hline PRC dry/wet & 2.65 & 10.25 & 20.7 & 27.95 & 19.2 & 10.0 & 9.25 \\
\hline
\end{tabular}


Table 3. Mean weight diameter (MWD) and contribution percentage of treatments compared with the control

\begin{tabular}{|l|c|c|}
\hline \multicolumn{1}{|c|}{ treatments } & MWD & $\begin{array}{c}\text { Contribution percentage of } \\
\text { treatments compared with } \\
\text { the control } \\
\%\end{array}$ \\
\hline Control & 0.545 & 0.00 \\
\hline CS & 0.552 & 1.3 \\
\hline CSC & 0.567 & 4.0 \\
\hline CSC dry/wet & 0.576 & 5.7 \\
\hline FS & 0.551 & 1.1 \\
\hline FSC & 0.565 & 3.7 \\
\hline FSC dry/wet & 0.575 & 5.5 \\
\hline HA & 0.565 & 3.7 \\
\hline HAC & 0.571 & 4.8 \\
\hline HAC dry/wet & 0.595 & 9.2 \\
\hline PR & 0.558 & 2.4 \\
\hline PRC dry/wet & 0.567 & 4.0 \\
\hline & 0.592 & 8.6 \\
\hline
\end{tabular}

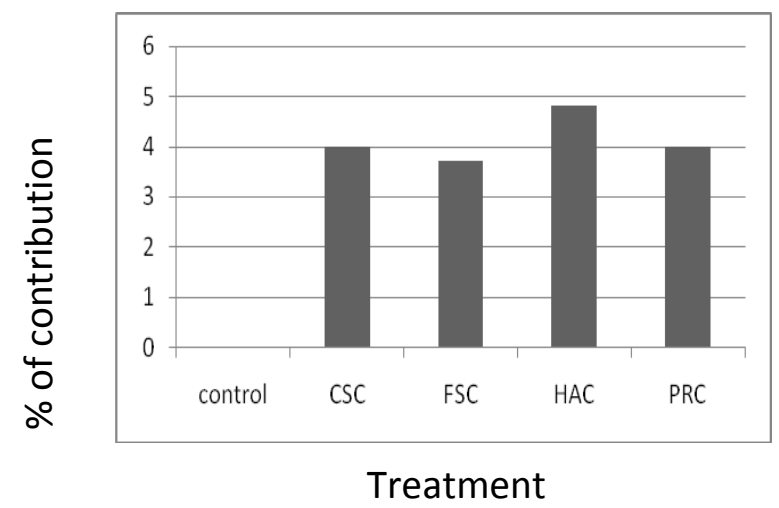

Figure 2. the contribution percentage of added materials plus clay.

\section{3- The effect of adding materials with clay under dry/wet cycles.}

Relative to the results after wet/dry cycles, generally, the MWD values were increased in all treatments compared with the control. In this concern, the best treatment was after humic acid plus $10 \%$ clay with wet/dry cycles whereas the contribution percentage was $9.2 \%$ compared with the control, followed by PRC dry/wet treatment whereas the contribution percentage was $8.6 \%$. (Table3 and Fig. 3). This may be attributed to the wetting which causes changes due to expansion of the electrical double layer, differential swelling, air entrapment and compression and heat wetting. Also, on drying, soil particles and aggregates re-orientate due to the effective stress of 
increasing soil water suction with the dispersed materials placed between coarser particles (Kay, 1990). This is more pronounced with clay content and humic acid, whereas the drying of soil increase bonding between soil organic matter and clay as water is consumed, thereby bringing soil organic matter into closer contact with the clay.

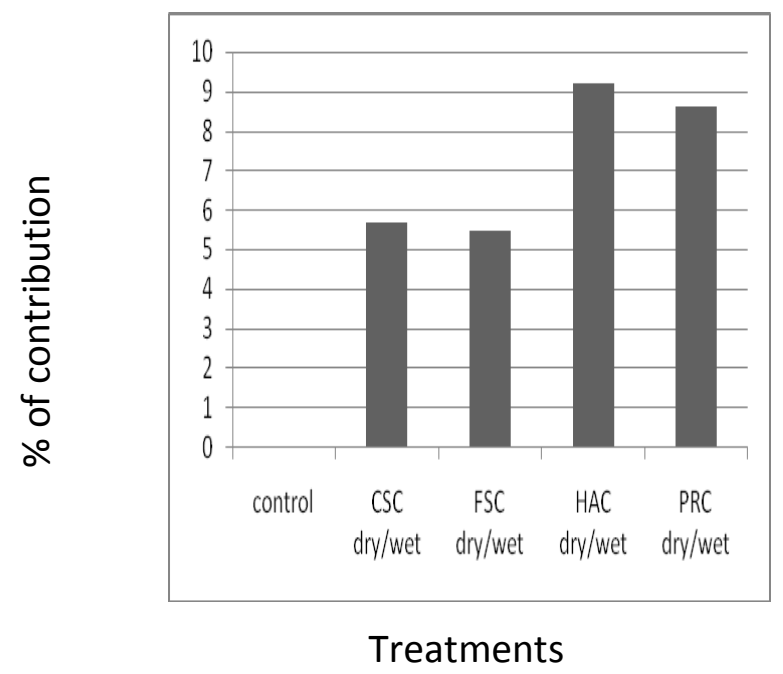

Figure 3. the contribution percentage of added materials with clay under the effect of dry/wet cycles.

\section{REFERENCES}

Bartoli, F. and S. Dousset (2011). Impact of organic inputs on wettability characteristics and structural stability in silty vineyard topsoil. European J. Soil Sci., 62, 2, $183-194$.

Bartoli, F., R. Philippy, and G. Buritin (1992). Poorly ordered hydrous Fe oxides, colloidal dispersion and soil aggregation. II. Modification of silty soil aggregation with $\mathrm{Fe}$ (III) polycations and model humic macromolecules. J. Soil Sci., 43, (1), $59-75$.

Kay, B. D. (1990). Rated of change of soil structure under different electrolytes. European J. Soil Sci., 12, $1-52$.

Klute, A. (1986). Methods of Soil Analysis. Part 1. Physical and Mineralogical Methods ( $2^{\text {nd }}$ ed.) Amer. Soc. Agron. Monograph No. 9 Madison, Wisconsin, USA.

Miller, W. P., R. L. Willis and G. J. Levy (1998). Aggregate stabilization in kaolintic soils by rates of anionic polyacrylamide. Soil Use and Management, 14( 2): $101-105$.

Page, A. L., R. H. Miller and D. R. Keeny (1982). Methods of Soil Analysis. Part П. Chemical and microbiological properties ( $2^{\text {rd }}$ ed.) Amer. Soc. Agron. Monograph no. 9 Madison, Wisconsin, USA. 
Puget, P., C. Chenu and J. Balesdent (1995). Total and young organic matter distribution in aggregates of silty cultivated soils. European J. Soil Sci., $46,3,449-459$.

Rechcigl, J. E. (1995). "Soil Amendments": Impacts on biotic systems. CRC press, Baca Raton, FL.

Six, J., Callewaeort P., Lenders S., DeGryze S., Morris S. J., Gregorich E. G., Paul E. A. and Paustian K. (2002). Measuring and understanding carbon storage in a forested soil by physical fractionation. Soil Sci. Soc. Am. J. 66: 1981-1987.

Soil Science Society of America (1997). Glossary of Soil Science Terms. Soil Science Society of America., Madison.

Tisdall, J. M., and J. M. Oades (1982). Organic matter and water stable aggregates in soils. J. Soil Sci., 33, (2), $141-163$.

Wagner, S., S. R. Cattle and T. Scholton (2007). Soil aggregate formation as influenced by clay content and organic matter amendment. J. Plant Nutr. Soil Sci., 170, $173-180$.

Xiao, C., Fauci, M., Bezdicek, D.F., McKean, W.T. and Pan, W.L. (2008) Soil aggregation and microbial responses to straw pupling byproducts. Soil Sci. Soc. Am. J. 72: 1471-1477.

Zhu, X.,H. Chen, W. Li, Y. He, P. C. Brookes and J. Xu (2014). Aggregation kinetics of nano-particles in different electrolytes. European J. Soil Sci. 65( 2): $206-217$.

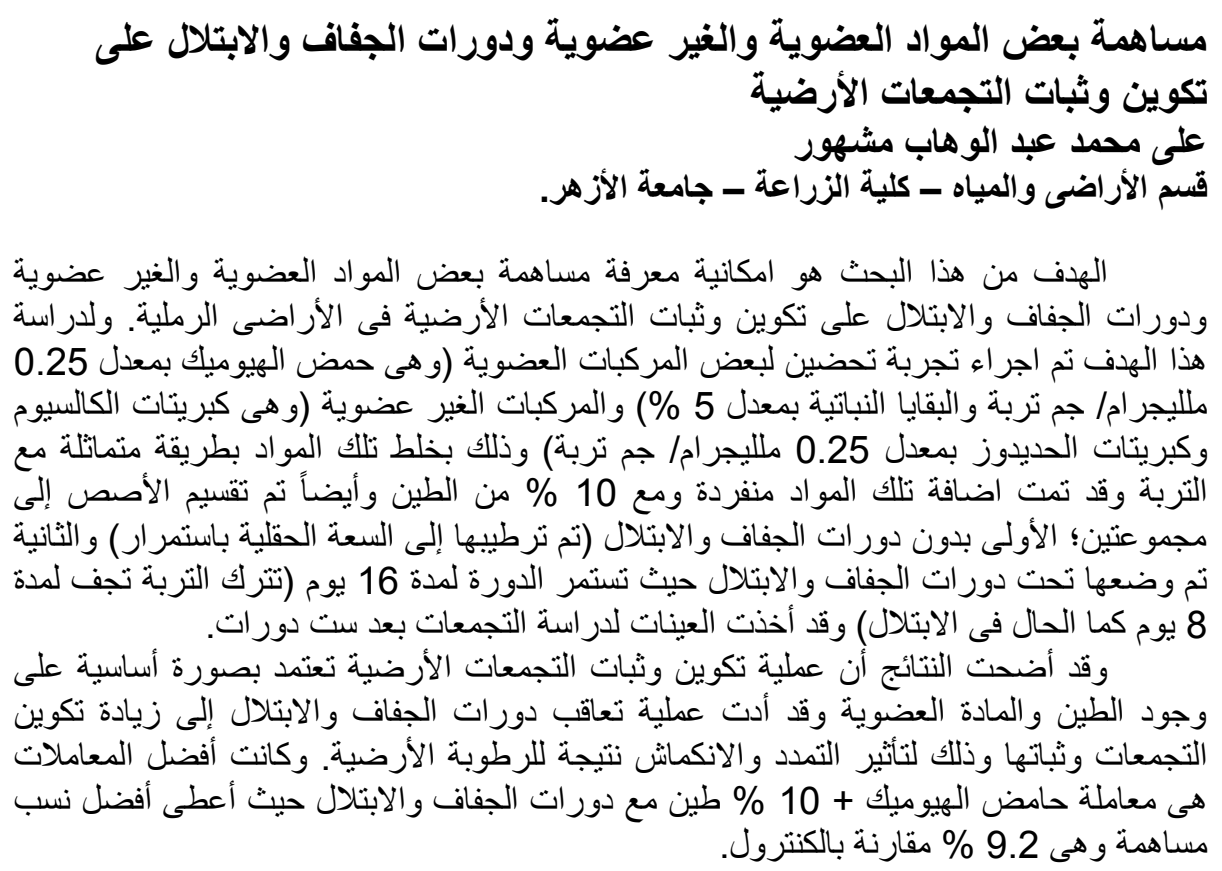

